\title{
Migrationspolitik in Deutschland und der Europäischen Union
}

\author{
Eine konstitutionenökonomische Analyse der Wanderung von Arbeitskräften
}

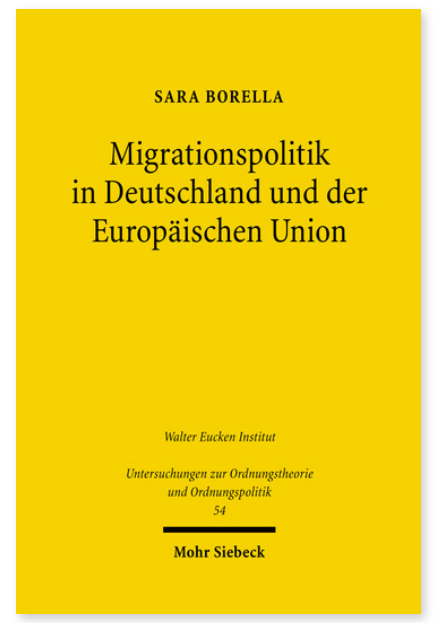

2008. XI, 259 Seiten. UOrd 54

ISBN 978-3-16-151479-1

DOI 10.1628/978-3-16-151479-1

eBook PDF 69,00€

ISBN 978-3-16-149645-5

fadengeheftete Broschur $69,00 €$
Die Wanderung von Arbeitskräften unter geeigneten Regeln stellt in Zeiten der Globalisierung ein Potential besonders für die alternden westlichen Demokratien dar, die miteinander im Wettbewerb um qualifizierte Arbeitskräfte stehen. Auf dieser Grundlage erarbeitet Sara Borella Kriterien für eine wünschenswerte Migrationspolitik in Deutschland und der Europäischen Union. Aus konstitutionenökonomischer Perspektive sind die ökonomische Rationalität und die gemeinsamen Interessen der Bürger eines Gemeinwesens gleichermaßen ausschlaggebend für politische Empfehlungen. Die ökonomische Analyse zeigt, dass Mobilitätshindernisse oft Ergebnis der Protektionsbestrebungen von Interessengruppen und nicht der Durchsetzung der allgemeinen Bürgerinteressen sind. Diese wären besser bedient, wenn Arbeitsmigration von der politisch bedingten Wanderung von Asylsuchenden und Flüchtlingen getrennt behandelt würde.

Arbeitsmigration wird gebraucht, und Einwanderungswillige sollten nicht mit Migrationsbarrieren ferngehalten werden. In ihren migrationspolitischen Empfehlungen wendet sich die Autorin gegen eine Auslegung der Migrationspolitik, die qualifizierte Einwanderungswillige behindert, und gegen eine Gemeinsame Migrationspolitik in der Europäischen Union, die auf Harmonisierung abzielt. Stattdessen kann ein Wettbewerb der nationalstaatlichen Migrationsregeln innerhalb der EU für die Bürger wünschenswert sein. Auf internationaler Ebene sollte sich die EU für Liberalisierungsschritte einsetzen, aber die Gründung einer neuen internationalen Organisation für Migration ist nicht zu empfehlen.

Die Arbeit wurde mit dem Wolfgang-Ritter-Preis 2008 der Wolfgang-Ritter-Stiftung Bremen ausgezeichnet.

Sara Borella Geboren 1972; 2000 Diplom in Wirtschaftswissenschaften an der Universitá di Parma; 2001-2008 Wissenschaftliche Mitarbeiterin am Institut für Allgemeine Wirtschaftsforschung, Abteilung für Wirtschaftspolitik an der Albert-Ludwigs-Universität Freiburg; 2007 Promotion; seit 2008 Forschungsreferentin am Walter-Eucken-Institut Freiburg.

Jetzt bestellen:

https://mohrsiebeck.com/buch/migrationspolitik-in-deutschland-und-der-europaeischen-union-9783161514791?no_cache=1 order@mohrsiebeck.com

Telefon: $+49(0) 7071-923-17$

Telefax: $+49(0) 7071-51104$ 